
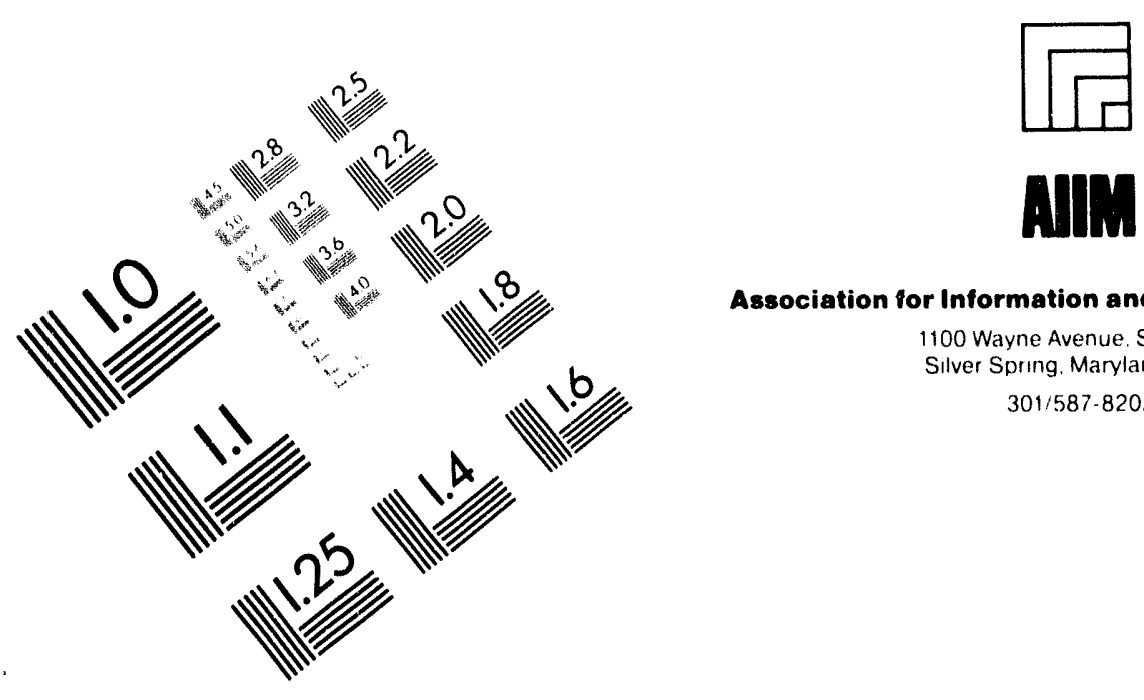

Association for Information and Image Management

1100 Wayne Avenue. Sulte 1100

Silver Spring. Maryland 20910

301/587-8202

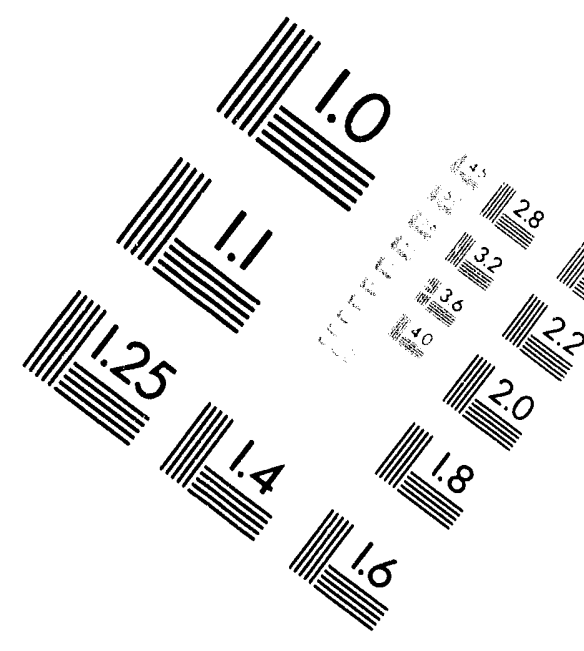

\title{
Centimeter
}

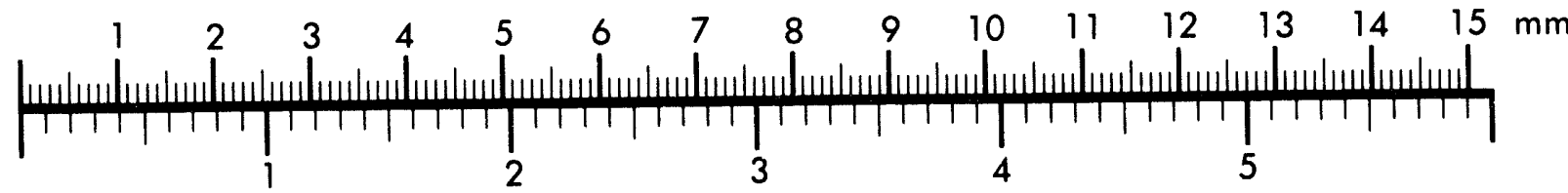

Inches
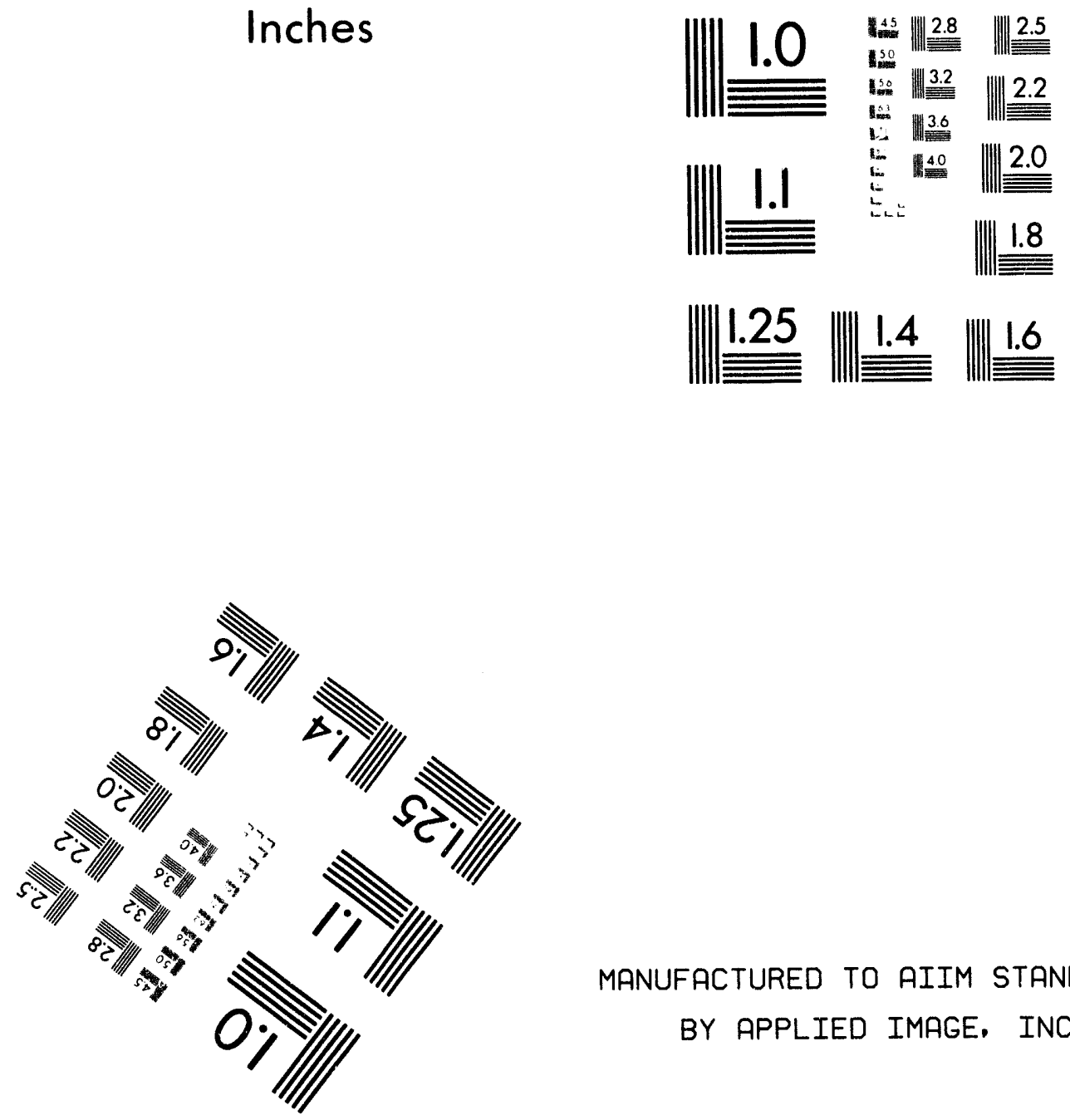

MANUFACTURED TO AIIM STANDARDS

BY APPLIED IMAGE. INC.

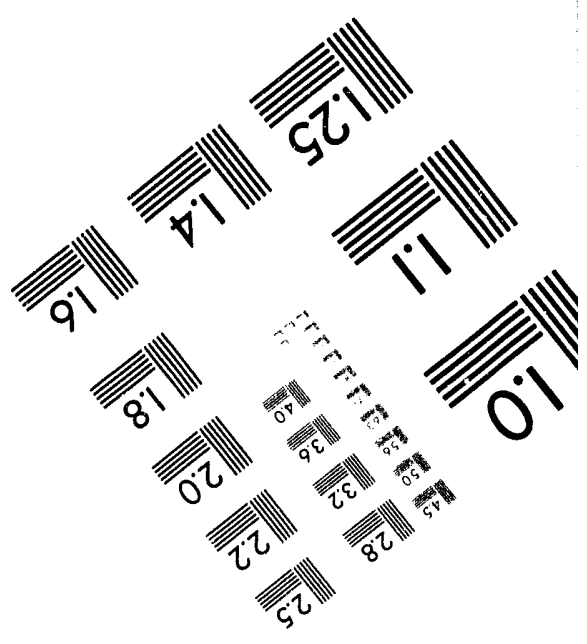



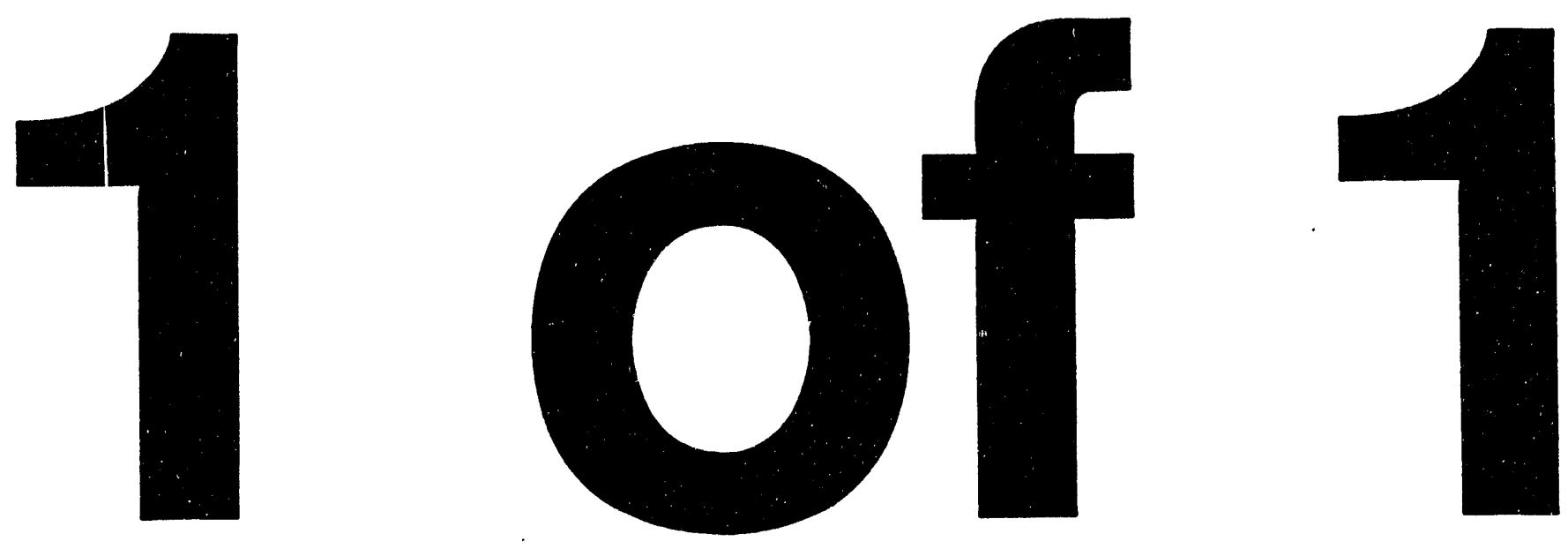


\title{
conf-9407/03-2
}

WSRC-MS-94-0383

\section{MATERIALS CONSIDERATIONS IN ACCELERATOR TARGETS}

by

Peacock, H.B.

Westinghouse Savannah River Company

Savannah River Site

Aiken, South Carolina 29808

lyer, N.C.

Louthan, Jr., M.R.

\section{DISCLAIMER}

\begin{abstract}
This report was prepared as an account of work sponsored by an agency of the United States Government. Neither the United States Government nor any agency thereof, nor any of their employees, makes any warranty, express or implied, or assumes any legal liability or responsibility for the accuracy, completeness, or usefulness of any information, apparatus, product, or process disclosed, or represents that its use would not infringe privately owned rights. Reference herein to any specific commercial product, process, or service by trade name, trademark, manufacturer, or otherwise does not necessarily constitute or imply its endorsement, recommendation, or favoring by the United States Government or any agency thereof. The views and opinions of authors expressed herein do not necessarily state or reflect those of the United States Government or any agency thereof.
\end{abstract}

\begin{abstract}
A document prepared for PROCEEDINGS OF THE INTERNATIONAL CONFERENCE ON
ACCELERATED-DIVISION TRANSULATION TECHNOLOG IES AND APPLICATIONS at Las Vegas, NV (USA) from 25 July - 28July 1994.
\end{abstract}

\section{DOE Contract No. DE-AC09-89SR18035}

This paper was prepared in connection with work done under the above contract number with the U.S. Department of Energy. By acceptance of this paper, the publisher and/or recipient acknowledges the U.S. Government's right to retain a nonexclusive, royalty-free license in and to any copyright covering this paper, along with the right to reproduce and to authorize others to reproduce all or part of the copyrighted paper.

$$
\text { da }
$$




\section{DISCLAIMER}

This report was prepared as an account of work sponsored by an agency of the United States Government. Neither the United States Government nor any agency thereof, nor any of their employees, makes any warranty, express or implied, or assumes any legal liability or responsibility for the accuracy, completeness, or usefulness of any information, apparatus, product, or process disclosed. or represents that its use would not infriage privately owned rights. Reference herein to any specific commercial product, process, or service by trade name, trademark, manufacturer, or otherwise does not necessarily constitute or imply its endorsement, recommendation, or favoring by the United States Government or any agency thereof. The views and opinions of authors expressed herein do not necessarily state or reflect those of the United States Government or any agency thereof.

This report has been reproduced directly from the best available copy.

Available to DOE and DOE contractors from the Office of Scientific and Technical Information. P. O. Box 62, Oak Ridge, TN 37831; prices available from (615) $576-8401$

Available to the public from the National Technical Information Service, U. S. Deparment of Commerce, 5285 Port Royal Rd., Springfield, VA 22161 


\title{
Materials Considerations in Accelerator Targets
}

\author{
H. B. Peacock, Jr., N. C. Iyer and M. R. Louthan, Jr. \\ Materials Technology Section, Savannah River Technology Center, \\ Westinghouse Savannah River Company, Aiken, SC 29808
}

\begin{abstract}
Future nuclear materials production and/or the burn-up of long lived radioisotopes may be accomplished through the capture of spallation produced neutrons in accelerators. Aluminum clad-lead and/or lead alloys has been proposed as a spallation target. Aluminum was the cladding choice because of the low neutron absorption cross section, fast radioactivity decay, high thermal conductivity, and excellent fabricability. Metallic lead and lead oxide powders were considered for the target core with the fabrication options being casting or powder metallurgy (PM). Scoping tests to evaluate gravity casting, squeeze casting, and casting and swaging processes showed that, based on fabricability and heat transfer considerations, squeeze casting was the preferred option for manufacture of targets with initial core cladding contact.
\end{abstract}

Thousands of aluminum clad aluminum-lithium alloy core targets and control rods for tritium production have been fabricated by coextrusion processes and successfully irradiated in the SRS reactors. Tritium retention in, and release from, the coextruded product was modeled from experimental and operational data. The model assumed that tritium atoms, formed by the $6 \mathrm{Li}(\mathrm{n}, \mathrm{a}) 3 \mathrm{He}$ reaction, were produced in solid solution in the $\mathrm{Al}-\mathrm{Li}$ alloy. Because of the low solubility of hydrogen isotopes in aluminum alloys, the irradiated $\mathrm{Al}$ Li rapidly became supersaturated in tritium. Newly produced tritium atoms were trapped by lithium atoms to form a lithium tritide. The effective tritium pressure required for trap or tritide stability was the equilibrium decomposition pressure of tritium over a lithium tritide-aluminum mixture. The temperature dependence of tritium release was determined by the permeability of the cladding to tritium and the local equilibrium at the trap sites. The model can be used to calculate tritium release from aluminum clad, aluminum-lithium alloy targets during postulated accelerator operational and accident conditions. This paper describes the manufacturing technologies evaluated and presents the model for tritium retention in aluminum clad, aluminum-lithium alloy tritium production targets.

\section{INTRODUCTION}

Conventional production of nuclear materials for atomic weapons has relied on neutron capture in specially designed targets exposed to a neutron flux in a nuclear reactor. Future nuclear materials production and/or the burn-up of long lived radioisotopes generated during previous production campaigns may be accomplished through the capture of spallation roduced neutron in accelerators. High energy protons from an accelerator bombard leac targets and cause spallation reactions that generate neutrons. The free neutrons strike aluminum-lithium targets located in blanket positions around the spallation targets. Both the lead and the aluminum-lithium target cores are clad and placed inside pressure tubes. The cladding material will be selected through evaluation of its nuclear, thermal and metallurgical properties and the cost and ease of fabrication.

Fabrication technologies for the spallation source target are not as well established as the aluminum clad aluminum-lithium core target technology. Coextrusion of a metallurgically bonded cladding over the very soft, low melting temperature lead will be 
extremely difficult. Without coextrusion or some other elevated temperature metal working process to break the protective oxide film on the clad material, a metallurgical bond between the clad and core is unlikely. The low melting temperature of lead precludes most of the elevated temperature working processes; thus, fabrication technologies which do not produce a clad-core bond may be required for the spallation target. Scoping experiments to establish the potential for direct casting and cold swaging of the spallation target were therefore conducted.

Fabrication of aluminum clad aluminum-lithium alloy targets from tritium is a proven technology which has been used at the Savannah River Site (SRS) for over thirty years. The primary target fabrication technology at SRS has been billet casting and coextrusion although direct casting, powder metallurgy and swaging technologies have also been applied. These technologies should be easily modified and transferred to a commercial fabricator for the production of accelerator targets. Billet casting and coextrusion will require only minor modifications before that technology is directly applicable to the fabrication of tritium producing, aluminum-lithium targets. Additionally, the SRS operating experience may be coupled with an understanding of tritium behavior in the target to provide the model necessary to predict tritium retention under postulated operating and accident conditions. This paper summarizes the results of the scoping experiments on fabrication of the spallation targets and presents a model for tritium retention in the aluminum clad aluminum-lithium alloy tritium production target.

\section{FABRICATION OF SPALLATION TARGET}

\section{Cladding Materials}

Cladding for the lead spallation target must have a low thermal neutron absorption cross section, an established data base for neutron damage, good weldability and workability, reasonable thermal conductivity, experienced significant use in accelerators and resist degradation in the accelerator environment. Potential cladding materials include aluminum and its alloys, Inconel and Type 304L stainless steel. Aluminum is the primary candidate because of the excellent experience base and its low neutron absorption cross section, fast radioactivity decay, high thermal conductivity, and excellent fabricability. However, aluminum alloys are very susceptible to mercury induced degradation processes such as liquid metal embrittlement and amalgamation.

Mercury is produced during the spallation of lead. The Spallation Induced Lithium Conversion (SILC) accelerator concept, for example, may produce about eight kilograms of mercury during six months of operation (1). The mercury content in the $24,000 \mathrm{kgs}$ of lead used in the SILC concept is only about $0.03 \mathrm{wt}$ \%; thus, most if not all the mercury should be soluble in the lead (2) and only the mercury vapor should be available for the degradation processes. The vapor pressure of mercury at $250^{\circ} \mathrm{C}$, a potential operating temperature for the spallation targets in the SILC concept, is about 9.9 $\mathrm{kPa}$. This pressure may be adequate to cause degradation of an aluminum cladding, if the protective oxide film were compromised. If mercury induced degradation of aluminum alloys is determined to be a significant problem, Inconel, or even Type 304 stainless steel, could become a compromise cladding candidate. However, mercury induced degradation and compromise of the aluminum cladding is currently considered to be unlikely and aluminum alloys remain the preferred cladding alloy and the only cladding material studied in these scoping experiments. 


\section{FABRICATION PROCESSES}

\section{Gravity Casting}

An aluminum clad- lead core target was fabricated by direct casting lead into a preheated Type 1100 aluminum alloy tube. The $41 \mathrm{~cm}$ long aluminum tube had a $2.4 \mathrm{~cm}$ outside diameter and a $0.35 \mathrm{~cm}$ wall. Molten lead, at approximately $400^{\circ} \mathrm{C}$, was bottom poured from a graphite crucible into the aluminum tube which had also been preheated to $400^{\circ} \mathrm{C}$. The pseudo target was air cooled (the lead solidified in approximately three minutes), then sectioned for evaluation. A small pipe formed at the top of the casting and, because of differences in thermal contraction during cooling, a gap developed between the lead core and the aluminum cladding.

The gap was measured by preparing vacuum/epoxy impregnated metallographic sections. The gap width in these right circular cylindrical sections was measured at an arbitrary position and at every $45^{\circ}$ from that position. The average gap width varied from $0.008 \mathrm{~mm}$ near the top of the target to $0.057 \mathrm{~mm}$ near the bottom. There were wide variations around the average and in isolated locations the lead wetted the aluminum forming a metallurgical bond, Figure 1. Typical gaps between the lead and aluminum are illustrated in Figure 2.

The maximum lead, or target centerline, temperature at any given set of accelerator operating parameters is a sensitive function of the gap width. Heat transfer across a gap decreases as the gap width increases and is improved if the gap contains helium rather than air or a vacuum. Parametric studies of the target centerline temperature as a function of gap width demonstrate that the calculated target centerline temperature in an Inconel 601 clad-lead core target increases from $220^{\circ} \mathrm{C}$ to $265^{\circ} \mathrm{C}$ as the gap size increases from $0.025 \mathrm{~mm}$ to $0.076 \mathrm{~mm}$ (Figure 3). This centerline temperature calculation was based on the assumption that heat is uniformly generated, $100 \mathrm{~W} / \mathrm{cm}^{3}$, within a one centimeter diameter lead target clad with $0.08 \mathrm{~cm}$ of Inconel 601 and exposed to cooling water at $90^{\circ} \mathrm{C}$. The calculated centerline temperatures for an aluminum clad target are anticipated to be lower because the $100^{\circ} \mathrm{C}$ thermal conductivity of aluminum $\left(235 \mathrm{~W} / \mathrm{m}^{\circ} \mathrm{C}\right)$ is significantly higher than that for Inconel $601\left(13 \mathrm{~W} / \mathrm{m}^{\circ} \mathrm{C}\right)$. In addition to affecting the margin against melting, the gap size may also affect the susceptibility to cladding degradation because the mobility of spallation products, including mercury, will decrease significantly as the temperature decreases. Therefore, fabrication techniques that minimize gap width may be desirable. Squeeze casting of pseudo target was therefore attempted.

\section{Squeeze Casting}

Squeeze casting is the process of solidifying metal under pressure. The high pressure promotes melt feed from hot spots to incipient shrinkage pores, keeps trapped gases in solution and promotes intimate contact between the casting (lead) and the tooling (the cladding).

A pseudo lead-aluminum target was squeeze cast by bottom pouring lead at $400^{\circ} \mathrm{C}$ into a system (an aluminum tube and associated tooling) that was preheated to $200^{\circ} \mathrm{C}$. A 8.6 $\mathrm{MPa}$ pressure was applied to the lead during solidification. The system preheat temperature was selected to assure that the $8.6 \mathrm{MPa}$ pressure did not deform the aluminum cladding. This casting process reduced the average gap but has little apparent affect on the tendency for the lead to wet the aluminum cladding. The average gap width 
varied from $0.004 \mathrm{~mm}$ near the bottom of the target to $0.016 \mathrm{~mm}$ near the target top. These gaps are partially due to thermal gradients that develop during solidification and to the differences in thermal expansion among lead and aluminum alloys. Similar thermal effects will develop in an operating target. Thus even if a zero gap target were fabricated, accelerator operation would produce a core-clad gap during cyclic operation without a metallurgical bond.

\section{Finite Element Analysis}

Finite element analysis was done to determine the clad-core response of a spallation target operating under hypothetical conditions. The analysis was for a target that had no gap between the Type 1100 aluminum cladding and pure lead core. This postulated zero gap, zero residual stress target was heated to steady state operation conditions where the centerline temperature was $250^{\circ} \mathrm{C}$ and the aluminum cladding was at $90^{\circ} \mathrm{C}$ at the coolant-clad interface. A linear radial gradient was imposed on the $150 \mathrm{~cm}$ long target and no axial or angular variations in temperature were assumed. Temperature dependent values for thermal expansion coefficients and yield strength were used in the calculation. Elastic-perfectly plastic material behavior was also assumed. The coefficient of friction at the clad-core interface was based on engineering judgment and was chosen to be 0.6 with a stiffness in stick of $1 \mathrm{MPa}$.

The finite element analysis showed that, at the operating conditions, the lead core expanded against the aluminum cladding with sufficient force to cause the lead to yield axially (Figure 3). This axial expansion is approximately $0.6 \%$ and creates a need for expansion chambers at the target ends. On cooling to room temperature, the lead is permanately defornied and has an axial plastic strain of $0.3 \%$, thus leaving a gap of approximately $0.0075 \mathrm{~mm}$ between the cladding and the core (Figure 4). Therefore, the minimum average gap sizes observed in both the gravity cast and the squeezed cast pseudo targets are similar to the gap that would developed during service, even if a zero gap target were fabricated. However, clad-core wetting could provide a metallurgical interface which may inhibit gap development during service.

\section{Cast and Swaged}

The strength of the lead-aluminum metallurgical interface was apparent is a gravity cast pseudo target which was cold swagged in an attempt to reduce the as fabricated gap size. The pseudo target was cast to duplicate the gravity cast target, than cold swagged in an attempt to reduce the as-fabricated gap size. The room temperature swaging process reduced the rod diameter by $9.6 \%$. Metallurgical evaluation of the swaged target showed that the gap width varied from $0.005 \mathrm{~mm}$ to $0.038 \mathrm{~mm}$. The swaging process caused fracture of the lead core underlying the wetted or metallurgically bonded regions (Figure 5).

A metallurgically bonded interface will improve heat transfer between the target core and cladding and therefore lower the centerline temperature of an operating spallation target. However, the metallurgical bond may also facilitate the core to clad migration of spallation products. Mercury, which is generated in the lead, could accumulate at the lead-aluminum interface. In contrast to the normal oxide film which prevents metallurgical contact between mercury and aluminum, this interface is not protective. Additionally, the aluminum will be in tension because of the thermal expansion gradients and the differences in thermal expansion. The combination of metallurgical contact with mercury and an operating tensile stress could cause liquid metal embrittlement and splitting of the aluminum cladding. This liquid metal embrittlement scenario has received only minimal attention. Until this potential 
degradation process is more fully understood, the satisfactory performance of a metallurgically bonded lead core-aluminum clad spallation target is questionable.

The tendency for metallurgical bonding at the clad core interface of a direct cast target can be minimized, if not eliminated through the use of aluminum tubing with anodized coatings on the interior surfaces. Nunerous commercial anodization processes are available. These processes can produce uniform, relatively defect free coatings similar to the 6000 angstrom thick coating shown in Figure 6. The actual thickness of coating required would be a compromise among the desire for a thin coating for heat transfer purposes and a thick coating to protect against metallurgical bonding. Other barrier layers, such as a nickel plate on the interior surface of the aluminum, may be effective in preventing degradation by the spallation products while permitting metallurgical bonding and thereby improving the heat transfer characteristics. However, the desirability of a metallurgical bond in the spallation target has not been established. This contrasts the aluminum clad-aluminum lithium tritium production target which is coextruded to assure a metallurgical bond at the clad-core interface.

\section{MODELING THE TRITIUM PRODUCTION TARGET}

The ability to accurately model tritium retention in, and release from, aluminum clad-aluminum lithium alloys is vital to the safe and efficient production of tritium in an accelerator. The Savannah River Site has used aluminum clad-aluminum lithium alloys for tritium production in heavy water reactors since the early 1950's. This operational experience has demonstrated that essentially all the tritium produced during irradiation is retained in the target until tritium extraction processes are initiated. The model developed in the following paragraphs provides the technical basis to calculate tritium release for the aluminum-aluminum lithium accelerator target as a function of the target temperature. Heat production in the tritium target is minimal, thus the target temperature may be considered to equal the temperature of the accelerator coolant.

\section{Model Development and Assumptions}

The flux of hydrogen through a metallic wall is dependent on the permeability (f) of the wall material, the area and thickness of the wall, and the driving force $(G)$, which is related to the difference in hydrogen activity on the entrance and exit surfaces. Permeability is simply the product of the diffusivity (D) and solubility (S). Hydrogen solubility can be related to either a real or an effective hydrogen pressure (p) on the wall. Permeability, diffusivity and solubility can be expressed as: $f=S D$, where

$$
\begin{aligned}
& D=D_{0} \exp \left(-Q_{d} / R T\right) \text { and } \\
& S=S_{0}(p)^{1 / 2} \exp \left(-Q_{S} / R T\right)
\end{aligned}
$$

The hydrogen pressure is generally assumed to be one in the expression for permeability.

Experiments to determine the permeability of metals and alloys to hydrogen isotopes generally involve the exposure of one side of a relatively thin, foil-like sample to gaseous hydrogen and the measurement of the hydrogen flux through the foil. Under these conditions, molecular hydrogen dissociates on the entrance surface, dissolves and diffuses as an atom or screened proton, reaches the exit surface and combines with another hydrogen atom to form a molecule. The driving force for such permeation is a function of the hydrogen pressure on the two sides of the foil, 


$$
\mathbf{G}=\sqrt{ } \mathbf{P}_{1}-\sqrt{P_{2}}
$$

If the hydrogen concentration on the exit side of the foil is zero, the driving force for permeation is $\sqrt{p}$, where $p$ is the hydrogen pressure, either real of effective, on the entrance side of the foil. The $\sqrt{p}$ relationship results because hydrogen is a diatomic gas molecules which dissolves as an atom.

The tritium $\left({ }^{3} \mathrm{H}\right)$ which is created in an $\mathrm{Al}-\mathrm{Li}$ alloy through the ${ }^{6} \mathrm{Li}(\mathrm{n}, \mathrm{a})^{3}$ the reaction is not in equilibrium with a real hydrogen pressure. However, if hydrogen is to remain in solution, a driving force, or effective hydrogen pressure, is required. The effective pressure is

$$
\mathrm{P}_{\text {eff }}=\left[\left(S_{\alpha} / S\right) \exp \left(-Q_{S} / \mathrm{RT}\right)\right]^{2}
$$

The concept of representing the hydrogen activity as an effective pressure has been used to describe hydrogen induced effects during cathodic charging, corrosion, and acid cleaning of metals (3-5).

The diffusion of hydrogen generally involves interaction of the absorbed hydrogen with lattice defects, including alloy and impurity atoms (6). The sites for such interactions are traps and the equilibrium hydrogen concentration in the vicinity of the trap may be significantly higher than the true lattice solubility. Trapping causes the effective diffusivity to decrease and the apparent solubility to increase but has no effect on steady state conditions (7).

Trapping of hydrogen isotopes in Al- $\mathrm{Li}$ alloys will increase the tritium retention capabilities of the alloys. This can be illustrated through calculations of tritium retention in the Mark 22 targets that have been extensively used for tritium production. given by

The average isothermal diffusion distance $(x)$ for hydrogen during time $(t)$ is

$$
x=\sqrt{D t}
$$

where $\mathrm{D}$ is the diffusivity of hydrogen. Hydrogen diffusivity in aluminum, calculated from permeation type measurements (6), is given by

$$
\mathrm{D}=0.011 \exp (-9,200 / \mathrm{RT}) \mathrm{cm} 2 / \mathrm{sec} \text {. }
$$

A tritium atom, formed by a $6 \mathrm{Li}(\mathrm{n}, \mathrm{a}) 3 \mathrm{H}$ reaction will begin to diffuse immediately after the nuclear reaction. The time required for tritium to migrate provides an estimate of the anticipated residence time for an untrapped tritium atom. These estimates show that without trapping, tritium atoms created within the targets would be released within days of operation at $100^{\circ} \mathrm{C}$. This contrasts the operational experience which demonstrates months of irradiation at $100^{\circ} \mathrm{C}$ without measurable tritium release to the moderator.

The importance of trapping to tritium retention in Al-Li targets was established during the early SRS operations (see References 9 and 10 for example). This early work lead to the conclusion that lithium tritide is formed during irradiation and that the reaction between lithium tritide and aluminum, 


$$
\mathrm{LiT}+\mathrm{Al} \rightarrow \mathrm{LiAl}+\mathrm{T}
$$

is the mechanism for release of tritium when the irradiated $\mathrm{Li}-\mathrm{Al}$ alloy targets are heated.

These early arguments provide a basis to model for tritium release from aluminum clad, Al-Li alloys by assuming:

1. local equilibrium is maintained amount the phases in the Al-Li alloy, (These phases are face-centered cubic aluminum containing both lithium and tritium in solid solution, the intermetallic, $\mathrm{LiAl}$, and lithium tritide),

2. the effective tritium pressure that establishes equilibrium pressure for decomposition of lithium tritide,

3. tritium release from the $\mathrm{Al}-\mathrm{Li}$ alloy is determined by permeation through the aluminum cladding,

4. the effective pressures controlling tritium permeation through the cladding are the equilibrium pressure for decomposition of lithium tritide at the entrance surface and zero as the exit surface,

5. neutron irradiaiton does not significantly alter the permeability of aluminum alloys to hydrogen isotopes,

6. the intermetallic, $\mathrm{LiAl}$ is present in the $\mathrm{Al}-\mathrm{Li}$ alloy throughout the irradiation process,

7. helium induced swelling and blistering are not a factor in tritium release, and

8. steady state permeation exists from the onset of irradiation.

The eight assumptions listed above are all included either directly or indirectly, in the model for tritium release illustrated in Figure 7.

\section{Model Calculations}

The temperature dependence of the equilibrium decomposition pressure was determined by a least squares fit of previously published data (11). The data was forced to an experimental function giving:

$$
P \text { equilibrium }=351 \exp (-10,700 / R T) \text { atm }
$$

where $\mathrm{H}$ is the activation energy for the decomposition reaction. Individual data points are shown in Figure 8

$$
P_{\text {equilibrium }}=351 \exp (-10,700 / R T) \mathrm{atm}
$$

The equilibrium decomposition pressure ( $\mathrm{P}$ equilibrium) represents the effective tritium pressure in the $\mathrm{Al}-\mathrm{Li}$ alloy.

The permeability of the cladding to tritium was calculated from previously published deuterium permeation data (8). The use of deuterium data should also provide an upper bound estimate of tritium permeation because classical isotope effects predict that the higher mass of the tritium atom will lower permeability. The permeability data 
used in the calculation were selected to minimize the potential for surface induced reductions in permeability. this selection was discussed in Reference 8 and the resulting permeability equation is

$$
f=1.9 \times 10^{-2} \exp (-22,400 / R T) \operatorname{cc}(N P T) a^{-1} / 2 \sec ^{-1} \mathrm{~cm}^{-1}
$$

This relationship may be combined with the anticipated cladding thickness, $x$, and the equation for the equilibrium decomposition pressure to obtain the temperature dependence of tritium release per square centimeter of target cladding. This maximum release rate, $R$, is given by

$$
R=(0.355 / x) \exp (-27,750 / R T) c c(N T P) \mathrm{cm}^{-2} \mathrm{sec}^{-1} \text {. }
$$

\section{CONCLUSIONS}

Scoping tests to evaluate gravity casting, squeeze casting, and casting and swagging processes suggest that, based on fabricability and heat transfer considerations, squeeze casting was the preferred option for manufacture of aluminum clad-lead spallation targets with zero initial gap. The interior of the aluminum cladding should be anodized prior to the casting operation to minimize mercury - aluminium reactions resulting from metallurgical bonding across the core-clad interface.

The technical basis to model tritium release from aluminum clad, aluminumlithium alloy targets as a function of temperature and clad thickness was developed. The model demonstrates that tritium release is governed by the equation:

$$
R=(0.035 / \mathrm{x}) \exp (-27750 / \mathrm{RT}) \mathrm{cc}(\mathrm{NTP}) \mathrm{cm}^{-2} \mathrm{sec}^{-1}
$$

where $\mathrm{x}$ and $\mathrm{T}$ are the clad thickness and temperature respectively.

\section{REFERENCES}

1) APT SILC Target Draft Preconceptional Design, APT Design Review Meeting March 1-4, 1993, Brookhaven National Laboratory, ATD/APT93-0007 (REV. 0).

2) Constitution of Binary Alloys, Max Hansen ed., Second Edition, p. 829, McGraw-Hill, New York, 1958

3) P. Rozenak and D. Eliezer, "Phase Changes Related to Hydrogen Induced Cracking in Austenitic Stainless Steels", Environmental Degradation of Engineering Materials III edited by M. R. Louthan, Jr., R. P. McNitt and R. D. Sission, Jr., The Pennsylvania State University, p 149, 1987.

4) C. B. Bargeron and R. C. Benson, LElectrochem Soc, Vol 119, p 1297, 1980.

5) R. Oriani and P. H. Josephic, Met. Trans, A. Vol 10A, p 1809, 1980 and J. W. Watson, Y. Z. Shen and M. Meshi. Met. Trans. A. Vol 19A, p 2299, 1988.

6) M. R. Louthan, Jr. and G. R. Caskey, Jr., International Joumal of Hydrogen Energy, Vol.1, p 291, 1976.

7) G. R. Caskey, Jr., and W. L. Pillenger, Met. Trans., Vol. 6A, p 467, 1975. 
8) M. R. Louthant, Jr., G. R. Caskey, Jr., and A. H. Dexter, Badiation Effects and Tritium Techmology for Fusion Reactors, Vol. 4, p IV-117, Proceedings of Intemational Conference held at Gatlinburg, TN, October 1975, Oak Ridge National Laboratory Report CONF-750989, March 1976.

9) L. H. Meyer and M. O. Fulda, Mode of Retention of Gases in Iradiated Li-Al Alloy. I-Distribution of Tritium and Helium Between Alpha and Beta Phases, DP-378, May 1959.

10) L. H. Meyer and M. O. Fulda, Mode of Retention of Gases in Irradiated Li-Al Alloy. Il-Reaction Between Lithium Tritide and Aluminum. DP-397, July 1959.

11) J. H. Owen and D. Randall, Radiation Effects and Tritium Technology for Eusion Reactors, Vol. 3, p III-433, Proceedings of International Conference held at Gatlinburg, TN, October 1975, Oak Ridge National Laboratory Report CONF-750989, March 1976.

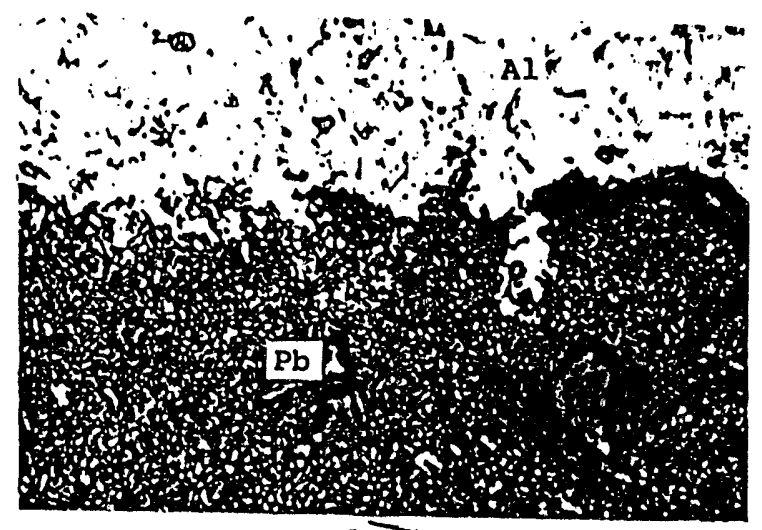

$$
\begin{aligned}
& \text { Figum 1. Typiad Mextlargind Bond } \\
& \text {.. formel an Gomity Cast Proud. Tanget }
\end{aligned}
$$

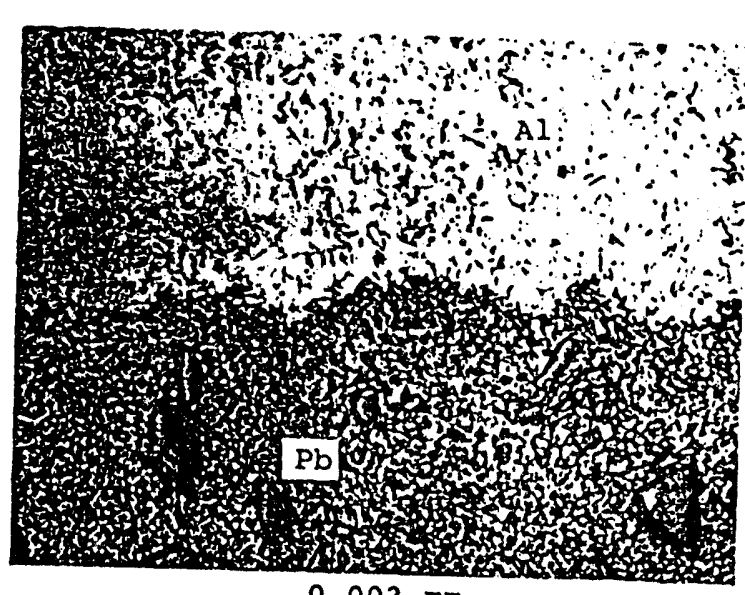

$0.003 \mathrm{~mm}$

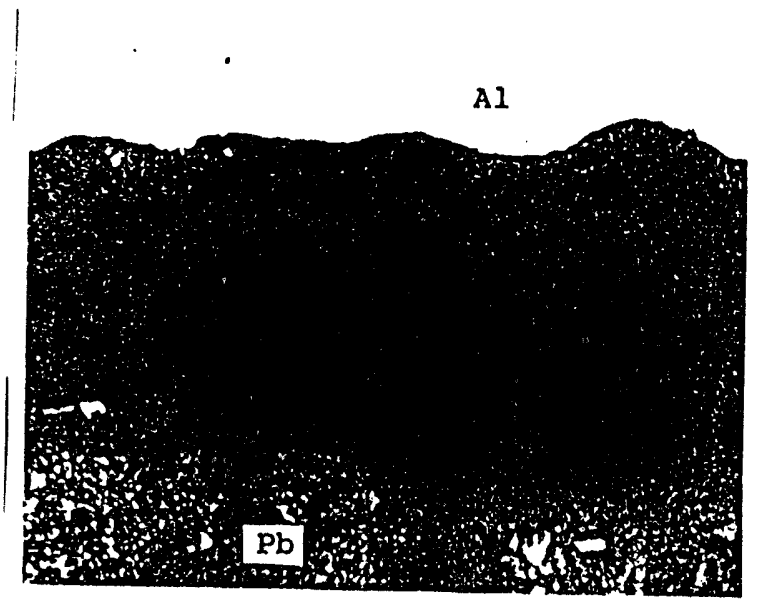

$0.043 \mathrm{~mm}$

$$
\begin{aligned}
& \text { Figure } 20 \text { Taps observed Between Core and cladding of As-Cast } \\
& \text { Spallation target } 1000 x \text { Magnification. }
\end{aligned}
$$



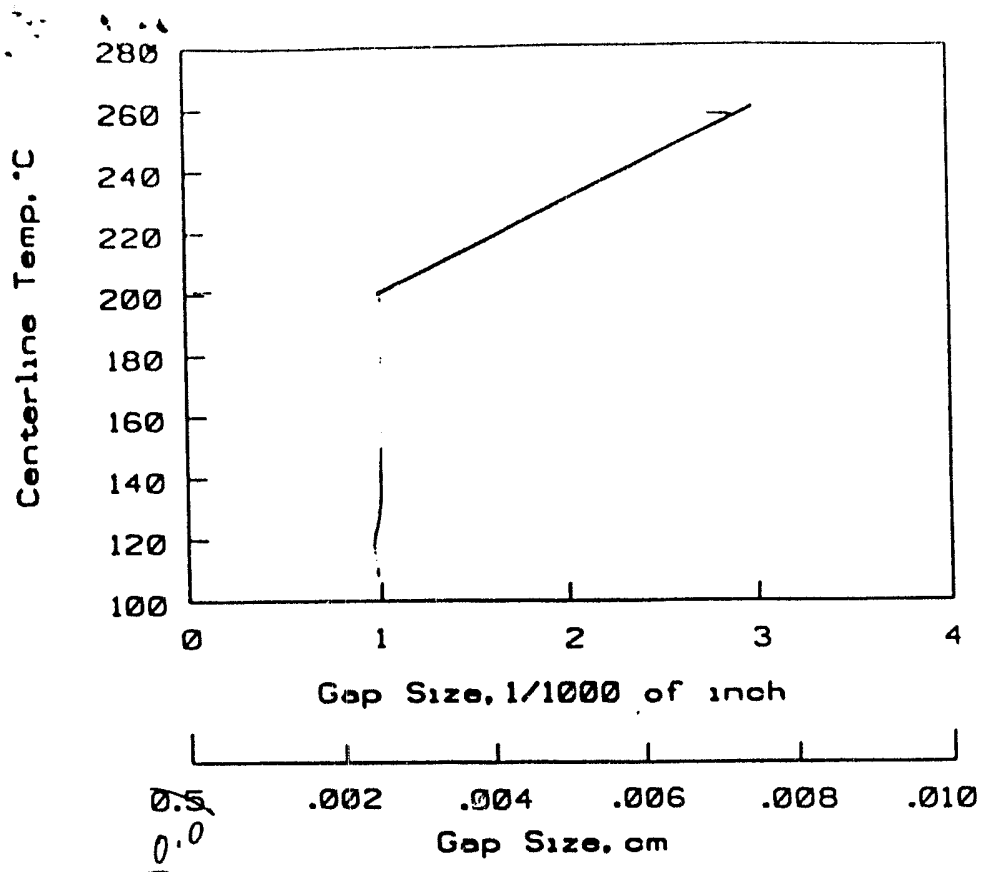

Figure 3 centerline Temperature vs. Gap size for Lead $(Q=100 \mathrm{w} / \mathrm{cc}$. Pellet Diameter=1.27 cm, Helium filled)

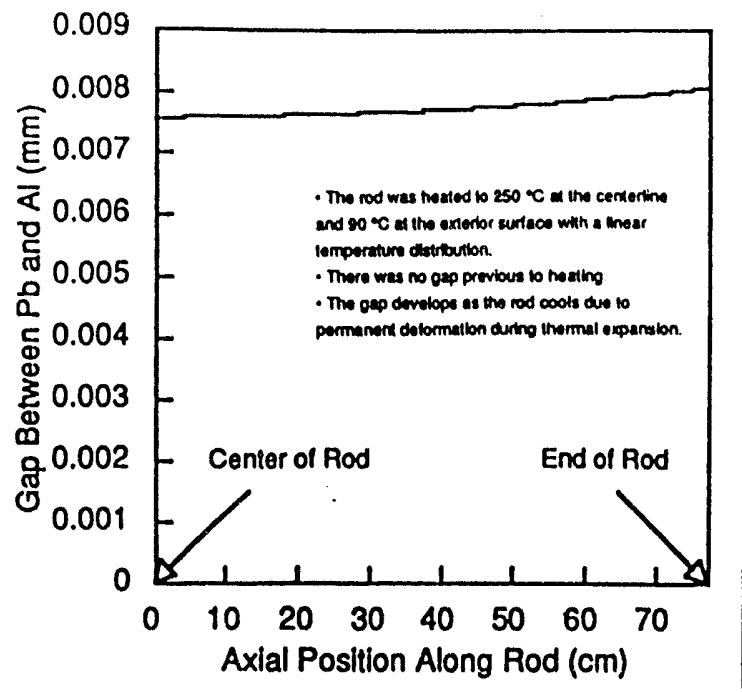

4

Figure The Material Interface Gap after Heating

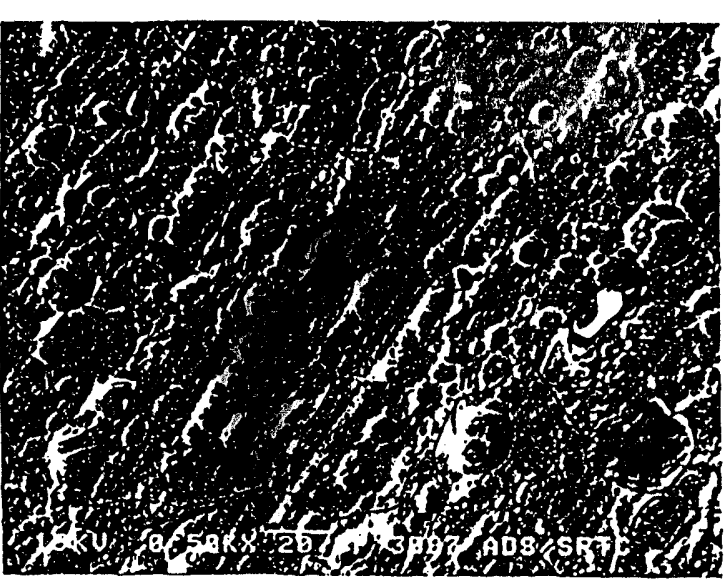

Figure $\frac{6}{9}$. Anodized Aluminum Surface (Porous Film) and Aluminum cladding.

Figure Cast and Swaged Spallation Target Indicating

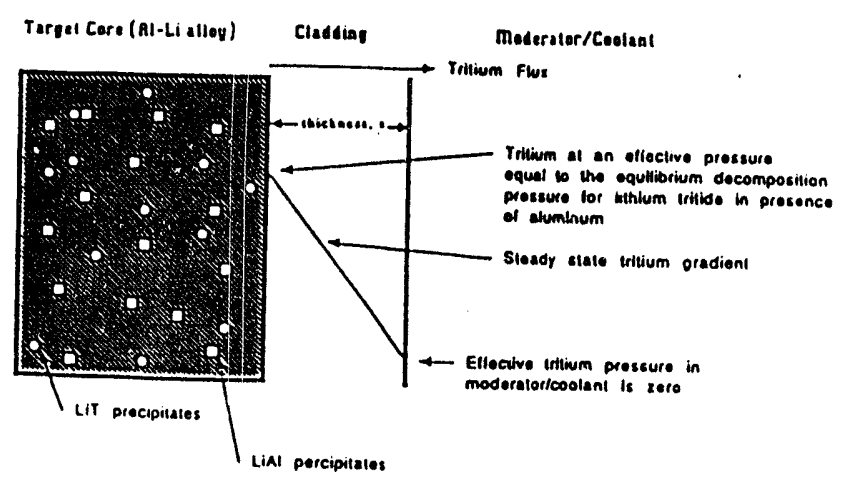

Figure7. Model for Tritium Retention in. and Release Grom. Al-Li Alloys

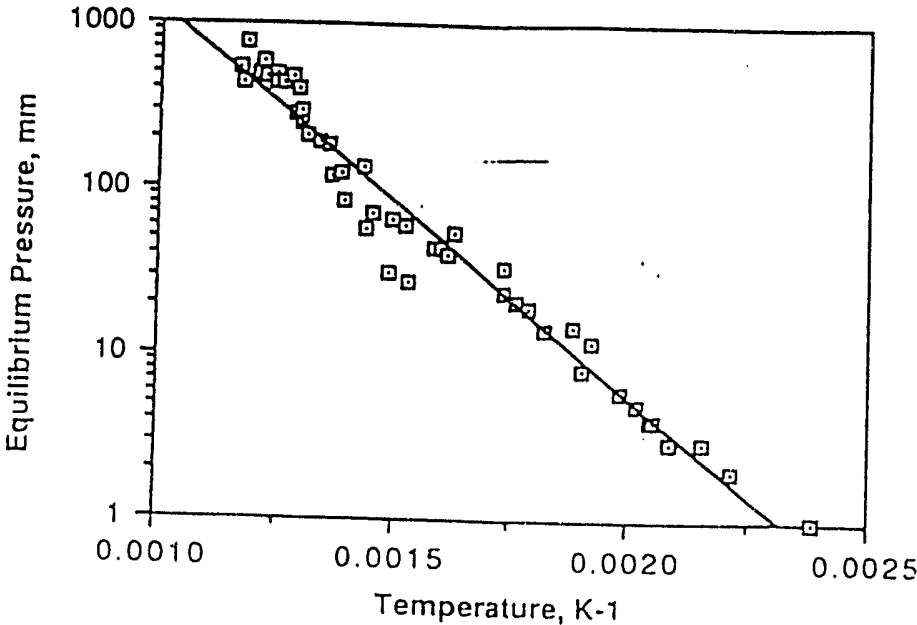

Figure 8. Temperature-Pressure Dependence of Decompositior. of Litheum Hydride 

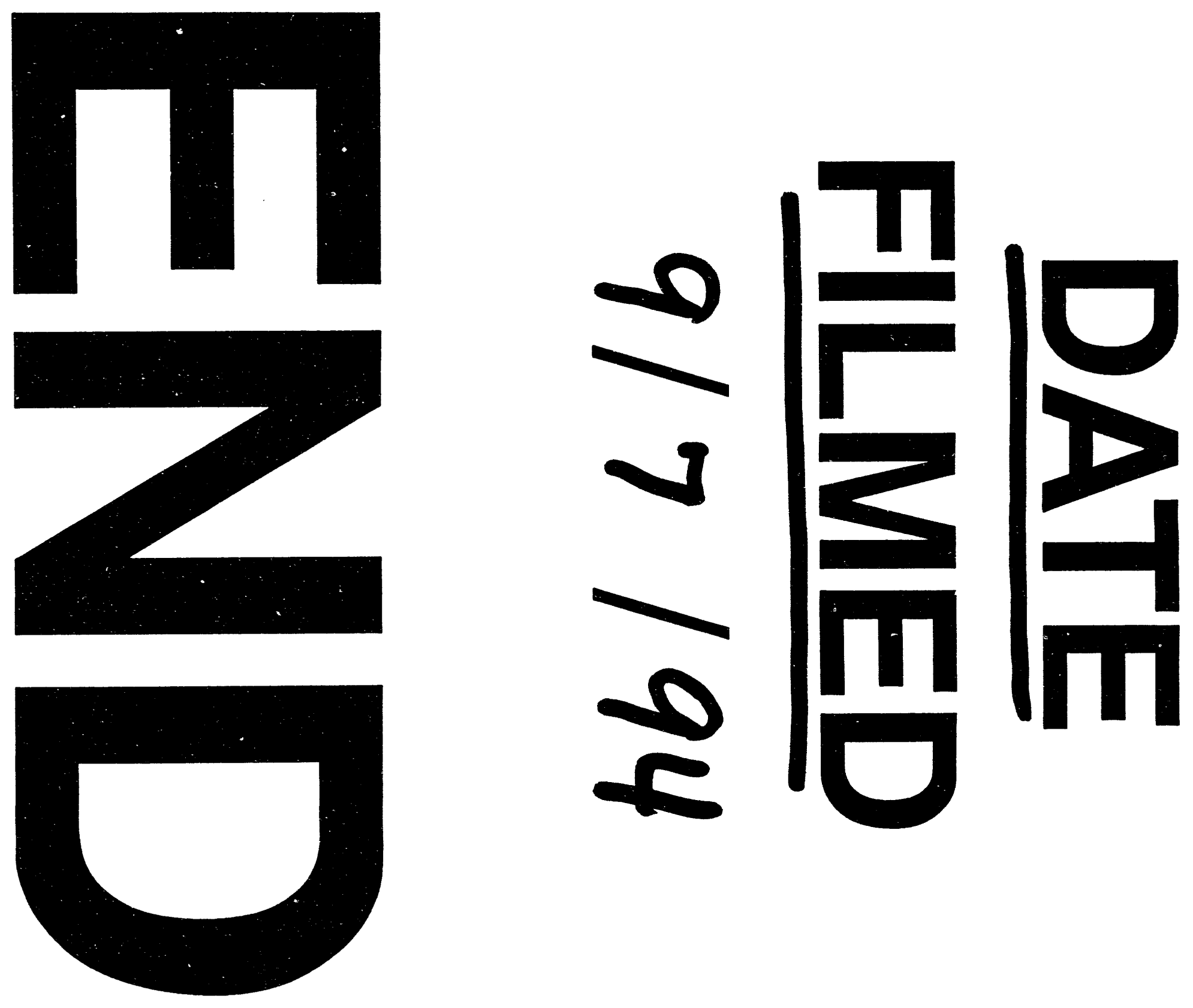


(1)

